\title{
Computational modelling, green synthesis and biological activity of arylsulfonilamides as NNRTIs against HIV-1
}

\author{
Anuradha Singh', Madhu Yadav ${ }^{1}$, Nidhi Singh', Ritika Srivastava', Rajinder Kaur², Satish K Gupta², \\ Ramendra K Singh ${ }^{1 *}$
}

From 2nd International Science Symposium on HIV and Infectious Diseases (HIV SCIENCE 2014)

Chennai, India. 30 January - 1 February 2014

\section{Background}

The development of new and potent anti-HIV compounds has become almost obligatory for the scientific community due to rapid emergence of drug resistant mutations. In pursuance of developing new anti-HIV molecules, we herein report the design, synthesis and anti-HIV properties of a series of potent arylsulfonilamide derivatives as NNRTIs.

\section{Methods}

Development of arylsulfonilamides as NNRTIs involved both the computational and synthetic methods. On the basis of extensive docking experiments, ten promising compounds out of $\mathbf{5 5}$ initially taken were synthesized using green protocols and their in vitro anti-HIV activity assessed in TZM bl cells by luciferase assay and reverse transcriptase (RT) inhibition assay against wild type HIV-1 RT.

\section{Results}

The compounds showed very promising in silico results as reflected by their lower $\Delta \mathrm{G}$ values-high binding affinity, significant scoring functions high RT- ligand stabilization energy and close interatomic contacts through strong H-bonds with Lys103, His235, Tyr318, Lys101 and Val179; pi-pi interaction with Tyr181 and pi-cation interaction through Lys101, which all together predicted high $\mathrm{EC}_{50}$ values. However, the molecules showed unimpressive inhibitory action against HIV-1 under in vitro conditions. The encouraging part of this study was that these

\footnotetext{
* Correspondence: rksinghsrk@gmail.com

${ }^{1}$ Nucleic Acids and Antiviral Research Laboratory, Department of Chemistry, University of Allahabad, Allahabad- 211002, India

Full list of author information is available at the end of the article
}

compounds behaved as NNRTIs as per our expectations, on the basis of results obtained during HIV-RT assay.

\section{Conclusions}

In the present study, it has been observed that promising in silico results are not always corroborated by the desired in vitro results. Nevertheless, it is a part and parcel of drug discovery process, where successful drug development is nearly a hard nut to crack.

\section{Authors' details \\ ${ }^{1}$ Nucleic Acids and Antiviral Research Laboratory, Department of Chemistry, University of Allahabad, Allahabad- 211002, India. ${ }^{2}$ National Institute of Immunology, Aruna Asaf Ali Marg, New Delhi, India.}

Published: 27 May 2014
doi:10.1186/1471-2334-14-S3-E4
Cite this article as: Singh et al:: Computational modelling, green synthesis and biological activity of arylsulfonilamides as NNRTIs against HIV-1. BMC Infectious Diseases 2014 14(Suppl 3):E4.

Submit your next manuscript to BioMed Central and take full advantage of:

- Convenient online submission

- Thorough peer review

- No space constraints or color figure charges

- Immediate publication on acceptance

- Inclusion in PubMed, CAS, Scopus and Google Scholar

- Research which is freely available for redistribution
( Biomed Central 